OPEN

SUBJECT AREAS:

ENVIRONMENTAL

HEALTH

ATTRIBUTION

Received

27 December 2013

Accepted

24 June 2014

Published

10 July 2014

Correspondence and requests for materials should be addressed to

T.A. (aki.takaya@ gmail.com)

\section{Role of climate variability in the} heatstroke death rates of Kanto region in Japan

\author{
Takaya Akihiko, Yushi Morioka \& Swadhin K. Behera
}

Application Laboratory, JAMSTEC, Yokohama, Japan.

The death toll by heatstroke in Japan, especially in Kanto region, has sharply increased since 1994 together with large interannual variability. The surface air temperature and humidity observed during boreal summers of 1980-2010 were examined to understand the role of climate in the death toll. The extremely hot days, when the daily maximum temperature exceeds $35^{\circ} \mathrm{C}$, are more strongly associated with the death toll than the conventional Wet Bulb Globe Temperature index. The extremely hot days tend to be associated with El Niño/Southern Oscillation or the Indian Ocean Dipole, suggesting a potential link with tropical climate variability to the heatstroke related deaths. Also, the influence of these climate modes on the death toll has strengthened since 1994 probably related to global warming. It is possible to develop early warning systems based on seasonal climate predictions since recent climate models show excellent predictability skills for those climate modes.

H eatstroke is a heat-related illness associated with the high body temperature, which has a high risk of health leading to death. A large number of heatstroke related deaths have been reported throughout the world; in particular, the heat waves at Chicago in $1995^{1}$ and France in $2003^{2}$ drew much attention of the media and society. Most of the casualties are elderly people who are extremely vulnerable to high temperature condition. To prevent those people from the heatstroke related deaths, it is important to examine the link of the climate to the heatstroke related deaths and provide a useful indicator for the heatstroke.

In Japan, the heatstroke during boreal summer has also become a serious social issue in recent years. Many studies on the heatstroke related death examined the relation with region, gender, and age, and reported a year-toyear increase in the death toll ${ }^{3,4}$. Also, other external factors such as indoor/outdoor environment, patient health condition, housing types, socio-economic levels, and air pollution were widely discussed ${ }^{5,6}$. Since 1994 , the death toll has dramatically increased, and several factors such as aging population and cataloging in the diagnosis were also suggested to contribute to this rise $\mathrm{f}^{7}$. In particular, Kanto region suffers the highest death toll by heatstroke (Fig. 1). The death toll by heatstroke is expected to increase in the future if the surface air temperature continues to rise as a result of the global warming.

As one of the heatstroke indicators, the Wet Bulb Globe Temperature (WBGT ${ }^{9}$ ) index has been widely used in many countries. The WBGT index is calculated by weighting the dry-bulb temperature, wet-bulb temperature, and black-globe temperature. A previous study ${ }^{7}$ reported usefulness of this index by noting that the occurrence of heatstroke in Japan is more strongly related with the daily maximum WBGT index than the daily maximum temperature. However, the weights of these temperature parameters in calculation of the WBGT index are empirically determined and lack physical reasoning ${ }^{10}$. Also, it is inconvenient to measure the black-globe temperature in many circumstances. For the practical use, it is required to establish a simpler indicator for the heatstroke.

Furthermore, a large number of studies on the death toll by heatstroke have focused on the long-term trend ${ }^{4}$, but have not paid much attention to the year-to-year variability. In fact, some of the extreme cases are reported in individual years. The death toll was extremely high in 1994, 2007 and 2010, but was very low in 1998 and 2003 , showing a large interannual variability above the linear trend (Fig. 1). Also, extremely hot summers in those years are found to be associated with the La Nina phenomenon in the tropical Pacific and the positive Indian Ocean Dipole $\left(\mathrm{IOD}^{11}\right)$ in the tropical Indian Ocean ${ }^{12}$. In spite of that understanding of tropical climate teleconnection, few studies have actually examined the relationship between the tropical climate variability and the death toll by heatstroke. 


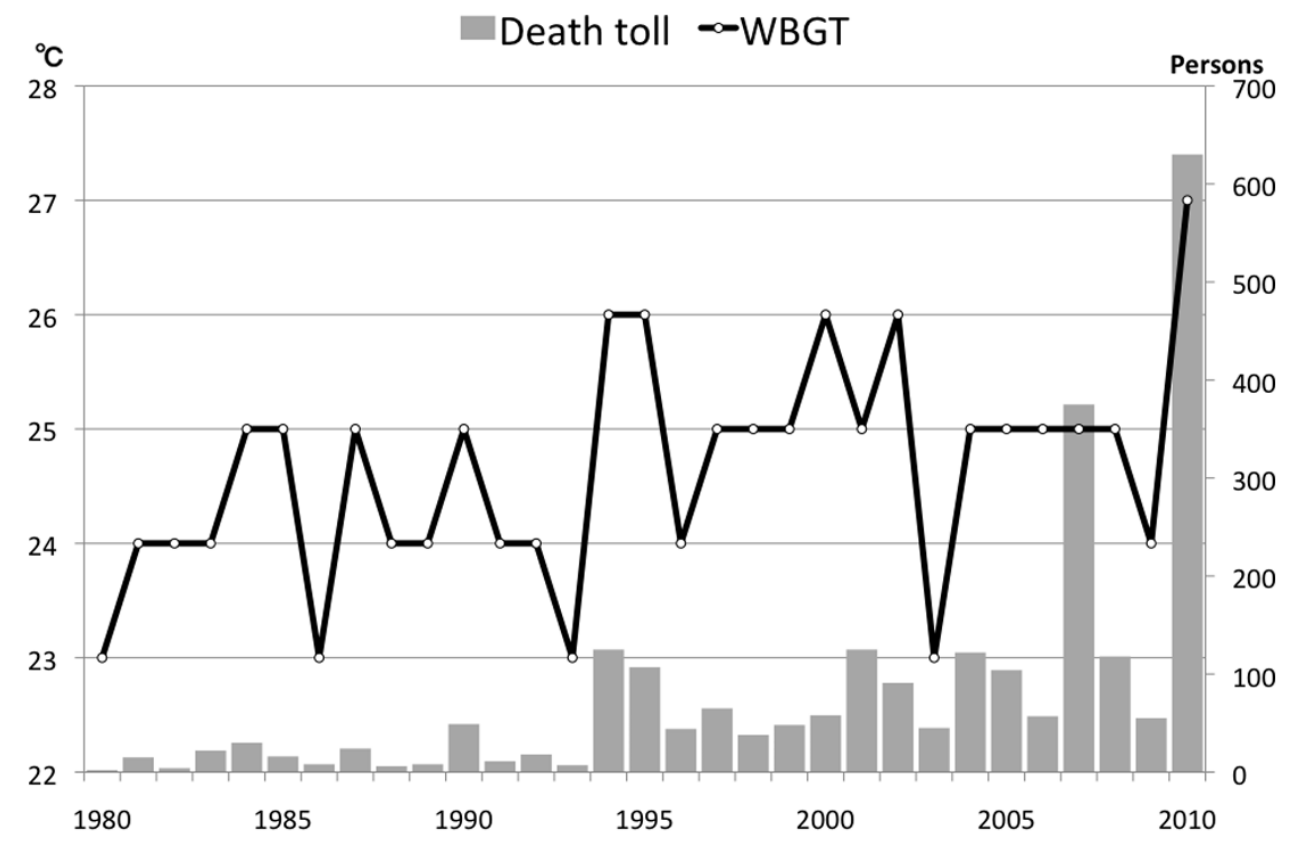

Figure $1 \mid$ Time series of the death toll by heatstroke (bar, in persons) and the WBGT index (solid line, in ${ }^{\circ} \mathrm{C}$ ) during boreal summer (July-August) of 1980-2010.

Therefore, this study aims to establish simpler indicator for the heatstroke than the WBGT index and reveal a possible link between the death toll by heatstroke in Kanto region and the tropical climate variability by using observational data. This paper is organized as follows. The data and analysis methods are described in Section 2. In Section 3, the relative contribution from the surface air temperature and humidity to the WBGT index variability is investigated, and its possible link with the tropical climate variability is examined. The results obtained are summarized and further discussed in Section 4.

\section{Possible factors for the death toll by heatstroke}

Interannual variability. Figure 1 shows time series of the death toll by heatstroke and the WBGT index estimated from the surface air temperature averaged in Kanto region during boreal summer. Similarly as in the case of the death toll, the WBGT index shows an increasing trend from 1980 to 2010 . In particular, the years exceeding the WBGT index of $25^{\circ} \mathrm{C}$, which is considered to be a borderline of the heatstroke warning ${ }^{7}$, undergoes a large interannual variability in addition to the remarkable increase in the number of death toll since 1994. For example, the WBGT index in 2010 is highest at $27^{\circ} \mathrm{C}$ and the death toll hit record high, whereas, in 2002 , the WBGT index is remarkably low at $23^{\circ} \mathrm{C}$ with few death toll. To examine the relation between the death toll by heatstroke and the WBGT index, correlation coefficient between the death toll and WBGT index anomalies was calculated (Table 1). The correlation coefficient between them is statistically significant and moderately high at 0.46 . The other heat stress index ${ }^{13}$ was also correlated with the death toll. But the correlation coefficient (0.35) was lower than that of the WBGT index.

To identify possible causes of the interannual variability in the WBGT index, we examined the link with the surface air temperature and humidity averaged in Kanto region during boreal summer of 1980-2010 (Fig. 2a). Throughout the period, the air temperature shows large interannual variability in addition to the general increasing trend. The correlation coefficient between the WBGT index and the air temperature anomalies is remarkably high at 0.9 (Table 1). The humidity also shows a decreasing trend over the study period. However, most importantly, it has also undergone a large internannual variation (Figs. 2a, b). The correlation coefficient between the
WBGT index and the humidity anomalies is significant but moderately high at -0.47 . The marked difference in the correlation coefficients suggests that the air temperature variability plays more important role in the interannual variability of the WBGT index than the humidity variability.

It is reported that the heatstroke related deaths tend to get triggered when the daily maximum temperature reaches $25^{\circ} \mathrm{C}$, and the death toll dramatically increases when the temperature exceeds 31 or $32^{\circ} \mathrm{C}^{7}$. This provides a further implication for a possible link between the daily maximum/minimum temperatures and the death toll by heatstroke. However, the correlation coefficient between the death toll and the daily maximum air temperature anomalies was low at 0.3 , whereas that with the daily minimum air temperature was at 0.3 (Table not shown). This apparent weak correlation suggests that other than the daily maximum or minimum air temperatures, there may exist other factors affecting the heatstroke related deaths.

These results motivate us to further investigate the relation with the number of "extremely hot days" with the daily maximum temperature exceeding $35^{\circ} \mathrm{C}$ and the number of "high temperature days" with the daily minimum temperature exceeding $25^{\circ} \mathrm{C}$. Both the number of the extremely hot days and the high temperature days are large in 1994 and 2010, whereas, in 2003, these are very small, indicating large interannual variability (Figs. 3 and 4). Throughout the analysis period, the correlation coefficient between the death toll and the number of extremely hot days is remarkably high at 0.76 (Table 2).

Table 1 | Correlation coefficients among the death toll by heatstroke, the WBGT index, the surface air temperature, and the humidity averaged in Kanto region during boreal summer (JulyAugust) of 1980-2010. The correlation coefficients before and after 1994 are shown, respectively. The asterisk indicates the significant coefficient exceeding the $90 \%$ confidence level by a twotailed t-test

\begin{tabular}{llccc} 
& & Before 1994 & After 1994 & \multicolumn{1}{c}{ Total } \\
\hline Death toll & WBGT & $0.50^{*}$ & $0.52^{*}$ & $0.46^{*}$ \\
WBGT & Temperature & $0.88^{*}$ & $0.93^{*}$ & $0.90^{*}$ \\
WBGT & Humidity & $-0.76^{*}$ & $-0.32^{*}$ & $-0.47^{*}$ \\
\hline
\end{tabular}



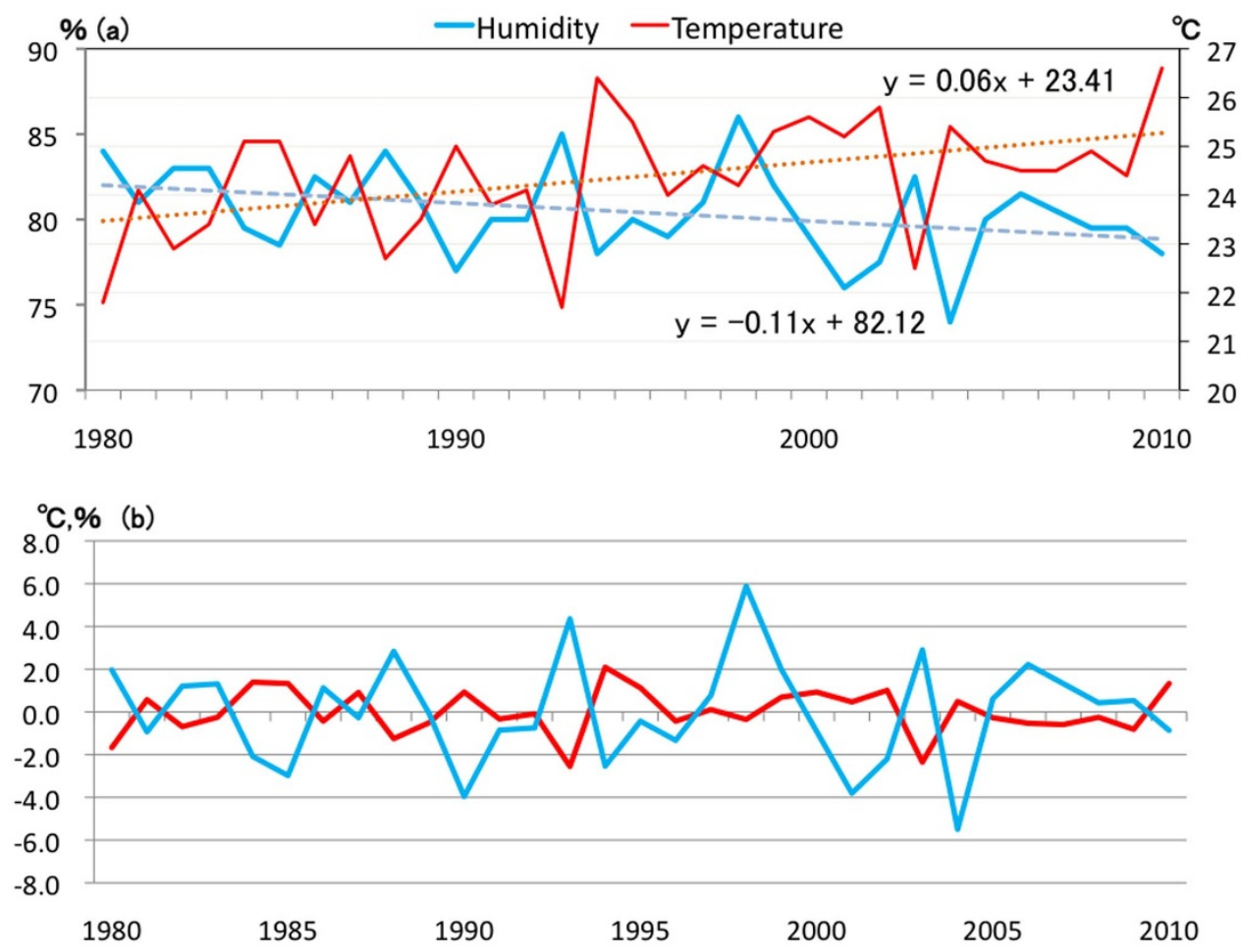

Figure $2 \mid$ (a) Time series of the surface air temperature (red line, in ${ }^{\circ} \mathrm{C}$ ) and the humidity (blue line, in \%) averaged in Kanto region during boreal summer (July-August) of 1980-2010. (b) Same as in (a), but for the anomalies.

This is higher than the correlation between the death toll and the conventional WBGT index, indicating that the number of extremely hot days may be a better indicator for the heatstroke related deaths. In contrast, the correlation coefficient between the death toll and the number of high temperature days is relatively small at 0.49 . These analyses suggest that the death toll is highly related to the number of extremely hot days rather than that of high temperature alone.
Finally, a possible link with the tropical climate variability such as the ENSO and the IOD is examined to find causes of the interannual variability in the number of extremely hot days. Figure 5 shows time series of the IOD and NINO 3.4 indices during boreal summer (JulyAugust) of 1980-2010. 3 out of 6 positive IOD events (in 1983, 1987, 1994) show more number of the extremely hot days, whereas, 1 out of 4 La Niña events (in 2010) shows an excess number of the extremely

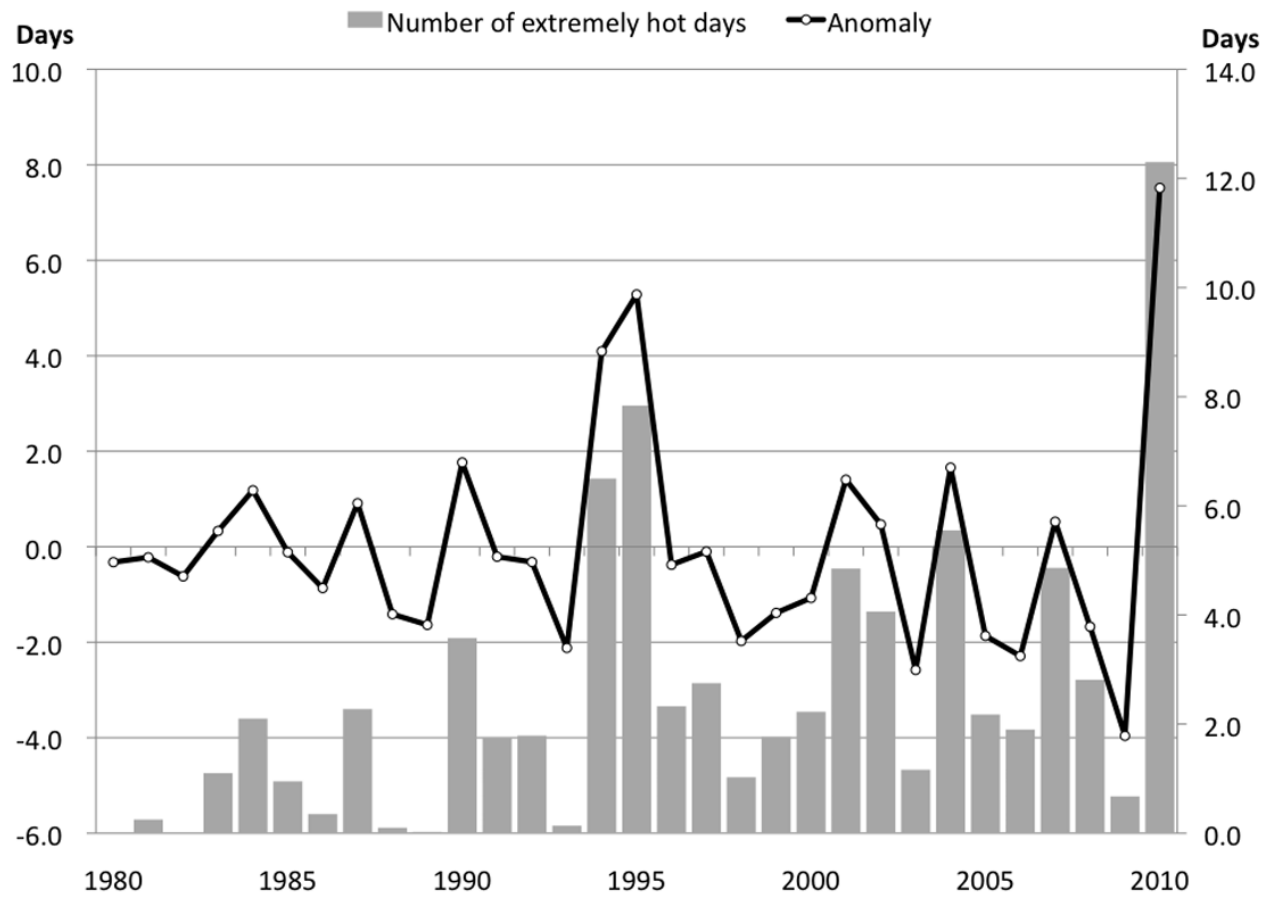

Figure $3 \mid$ Time series of the number of extremely hot days (bar, in days) and its anomaly (solid line, in days) averaged in the Kanto region during boreal summer (July-August) of 1980-2010. 


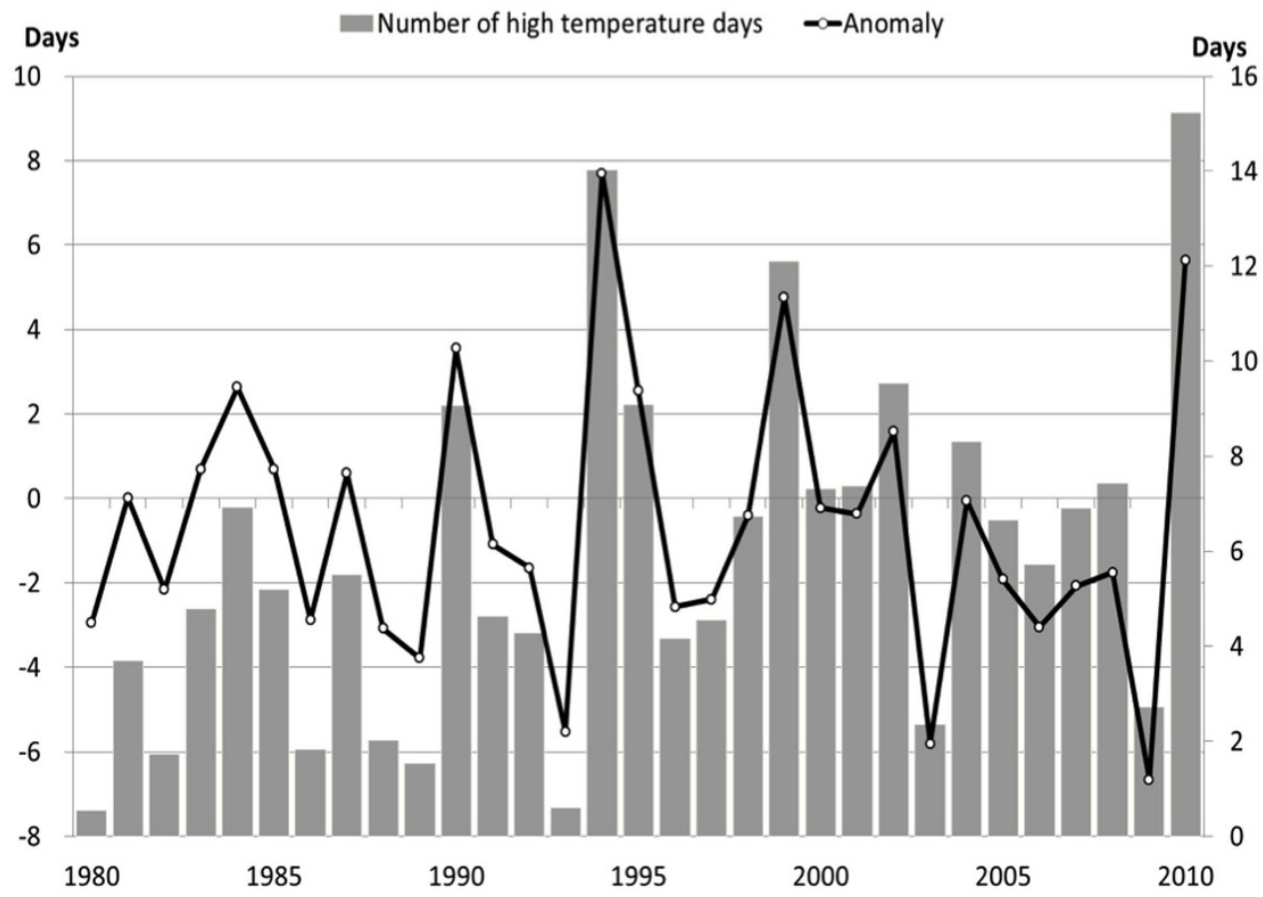

Figure 4 Same as in Fig. 3, but for the number of high temperature days (bar, in days) and its anomaly (solid line, in days).

hot days. This suggests that the excess number of extremely hot days tends to be more frequently associated with the positive IOD than ENSO, though this relation is not so apparent in the correlation coefficient for the whole period such that it is low at 0.17 for the IOD index and -0.09 for NINO 3.4 index (Table 2). Since the IOD starts to develop from the boreal summer, the IOD is more likely to have influence on the summertime air temperature in Kanto region.

Decadal shift in 1994. Compared to the period before 1994, the death toll by heatstroke dramatically increases after 1994 (Fig. 1), indicating occurrence of decadal shift. However, the correlation coefficient between the death toll and the WBGT index shows no marked difference before and after 1994 (Table 1). This suggests another possible factor responsible for the stronger coupling between climate variations and extremely hot days, and hence this dramatic increase in the death toll. Interestingly, the correlation between the death toll and the number of extremely hot days becomes stronger since 1994. The correlation coefficient before 1994 is moderately high at 0.54 , whereas it becomes remarkably high at 0.79 after 1994 . Also, the years when both the death toll and the number of extremely hot days increase were 6 years in 1994, 1995, 2001, 2004, 2007, and 2010. On the other hand, before 1994, they were just 3 years in 1984, 1987, and 1990. The increase in the number of coincident years may be responsible for the higher correlation after 1994. These results suggest that since 1994, the number of extremely hot days more strongly affects the death toll

Table 2 | Same as in Table 1, but for the extremely hot days and the high temperature days averaged in Kanto region, and the IOD and NINO3.4 indices during boreal summer (July-August) of 19802010

\begin{tabular}{llccc} 
& & Before 1994 & After 1994 & Total \\
\hline Death toll & Extremely hot days & $0.54^{*}$ & $0.79 *$ & $0.76^{*}$ \\
Death toll & High temperature days & $0.52^{*}$ & $0.54^{*}$ & $0.49 *$ \\
IOD & Extremely hot days & 0.20 & 0.17 & 0.17 \\
NINO 3.4 & Extremely hot days & 0.30 & -0.21 & -0.09 \\
\hline
\end{tabular}

than the WBGT index and contributes to the increase in the death toll by heatstroke.

\section{Summary and Discussion}

By using the observational data during boreal summer of 1980-2010, we investigated interannual variability of the death toll by heatstroke in Kanto region and its possible link with the tropical climate variability. The results show that over the analysis period, the death toll by heatstroke is highly correlated with the number of extremely hot days in which the daily maximum temperature exceeds $35^{\circ} \mathrm{C}$. The high correlation is retained to a great extent by even excluding the highest death toll in 2010 from the analysis (Table not shown). Also, the correlation coefficient with the number of the extremely hot days is much higher $(0.76)$ than that with the conventional heatstroke indicator, the WBGT index (0.46). Furthermore, the excess number of extremely hot days is found to be more frequently associated with the IOD than the ENSO. As such, the death toll by heatstroke may have a link with the tropical climate variability via the number of extremely hot days.

Another interesting finding in this study is that the death toll shows a decadal shift in 1994, when the death toll increases dramatically. Although the conventionally used WBGT index does not show any significant shift in the correlation with the death toll, the number of extremely hot days shows higher correlation with the death toll after 1994

One may argue that the heatstroke related death could occur even at lower temperatures if the event lasts over a number of days rather than a short extremely hot event. To examine this possibility, we have estimated the number of consecutive days over $30^{\circ} \mathrm{C}$ and found that the correlation coefficient with the death toll over the analysis period is 0.53 . This is not as high as the case for the extremely high temperature days (Table 2). Therefore, the number of extremely hot days has more effect on the death toll than a longer spell of relatively less hot days.

The results obtained in this study suggest that the extremely hot days may be a better indicator for the heatstroke than the conventional WBGT index. Also, the tropical climate variability such as the IOD and ENSO may have a link with the extremely hot days in Kanto region through the atmospheric teleconnection ${ }^{12}$. In the future 

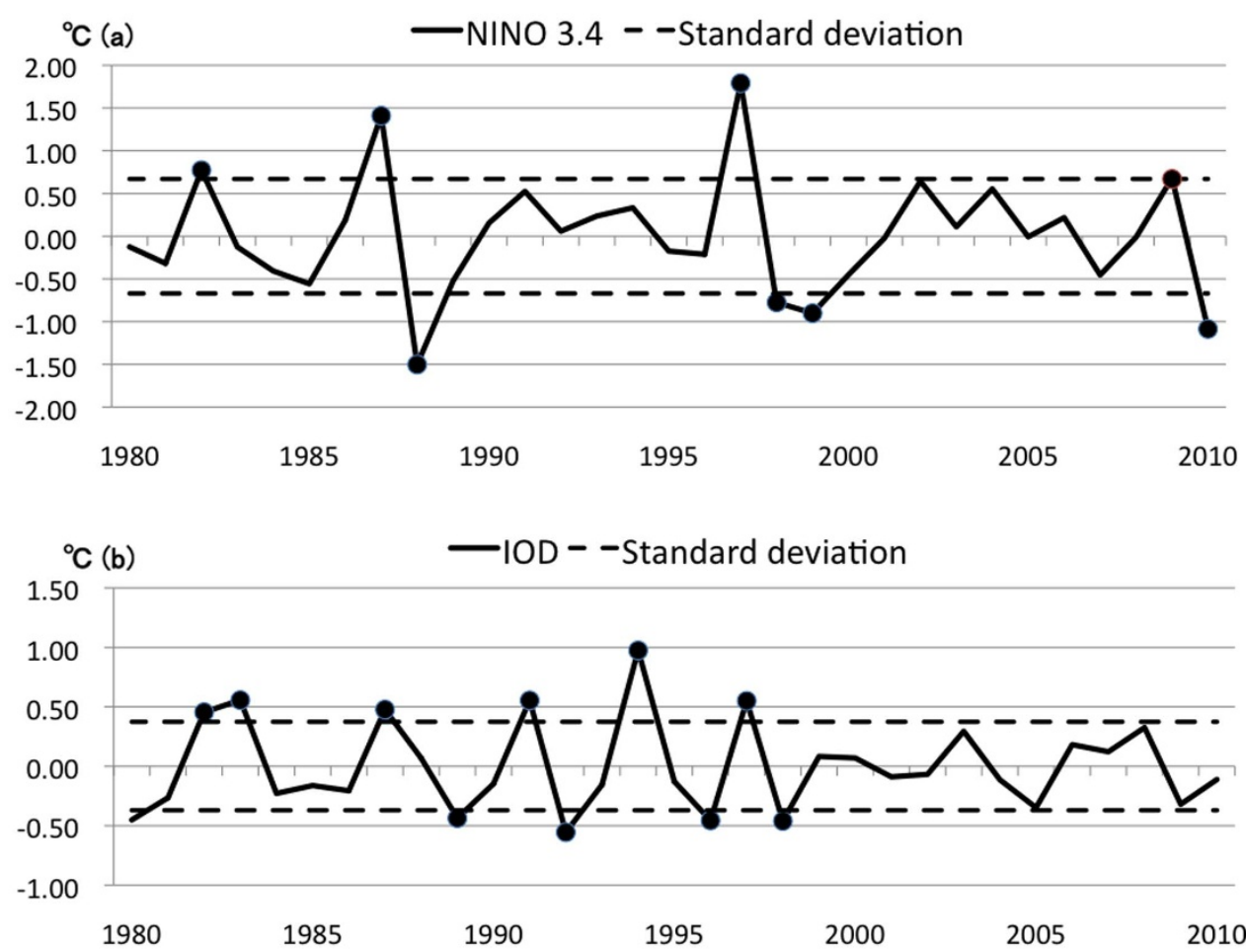

Figure $5 \mid$ (a) Time series of the NINO3.4 index (solid line, in ${ }^{\circ} \mathrm{C}$ ) during boreal summer (July-August) of 1980-2010. The broken line indicates the standard deviation. (b) Same as in (a), but for the IOD index (solid line, in ${ }^{\circ} \mathrm{C}$ ).

warming climate, even a small temperature perturbation related to the tropical climate variability may lead to occurrence of the extremely hot days. Therefore, it is urgent to provide accurate predictions of the extremely hot days to the local society. For this warning system, we need to accurately predict the local air temperature in Kanto region by using a regional model based on the forecasts of a coupled general circulation model, which realistically simulates the tropical climate variability.

\section{Methods}

Data. We use the observed surface air temperature and humidity data from the AMeDAS full data set Ver. 3 provided by the Japan Meteorological Business Support Center (http://www.jmbsc.or.jp). Daily averaged data at 78 points in Tokyo and 6 other prefectures in Kanto region, excluding Izu and Ogasawara islands, are analyzed. The analysis period is boreal summer (July-August) of 1980-2010. Also, we use the monthly Sea Surface Temperature (SST) data from the HadISST ${ }^{14}$ provided by the UK Met Office Hadley Center. The horizontal resolution of the SST data is $1^{\circ} \times 1^{\circ}$, and the analysis period is the same as the meteorological data. In order to examine a possible link with the tropical climate variability such as El Niño/Southern Oscillation (ENSO), we calculated NINO3.4 index defined as the averaged SST in the tropical Pacific $\left(120^{\circ} \mathrm{W}-170^{\circ} \mathrm{W}, 5^{\circ} \mathrm{S}-5^{\circ} \mathrm{N}\right)$. Similarly, for the IOD, we calculated the IOD index defined as the SST difference between the western and the eastern tropical Indian Oceans $\left(50^{\circ} \mathrm{E}-70^{\circ} \mathrm{E}, 10^{\circ} \mathrm{S}-10^{\circ} \mathrm{N} \text { and } 90^{\circ} \mathrm{E}-110^{\circ} \mathrm{E}, 10^{\circ} \mathrm{S}-0^{\circ}\right)^{11}$.

Furthermore, we use the WBGT index for the reference of heatstroke indicator. The WBGT index in Kanto region was estimated from the averaged surface air temperature and humidity, by using the WBGT index table provided by Japanese Society of Biometeorology (http://www.med.shimane-u.ac.jp/assoc-jpnbiomet). For comparison with the WBGT index, we used other heat stress index ${ }^{13}$, which is calculated by using air temperature and water vapor pressure. Also, the death toll by heatstroke in Kanto region is based on Population Dynamics of Statistics provided by the Ministry of Health, Labor and Welfare (see Acknowledgement). It should be noted that due to the limitation of the available data, the supplementary Population Dynamics data was only used before 2002. For calculation of the liner trend, we applied the least squared method, and the anomaly was calculated after excluding the liner trend and monthly climatology. Simple correlation analysis was conducted among different variables such as the WBGT index, air temperature, and humidity to understand the climate role in number of deaths by heatstroke.

1. Semenza, J. C. et al. Heat-related deaths during the July 1995 heat wave in Chicago. New Engl. J. Med. 335, 84-90 (1996).
2. Vandentorren, S. et al. August 2003 heat wave in France: risk factors for death of elderly people living at home. Eur. J. Public Health 16, 583-591 (2006).

3. Nakai, S., Ito, T. \& Morimoto, T. Deaths from heat-stroke in Japan: 1968-1994. Int. J. Biometeorol. 43, 124-127 (1999).

4. Fujibe, F. Long-term variations in heat mortality and summer temperature in Japan. Tenki 60, 371-381 (2013).

5. Piver, W. T., Ando, M., Ye, F. \& Portier, C. J. Temperature and air pollution as risk factors for heat stroke in Tokyo, July and August 1980-1995. Environ. Health Persp. 107, 911-916 (1999).

6. Miyake, Y. et al. Heatstroke study 2006 in Japan. Nihon Kyukyu Igakukai Zasshi 19, 309-321 (2008).

7. Ono, M. Global warming and heat disorders. Chikyu-kankyo 21, 263-270 (2009).

8. Ministry of the Environment. Wise adaptation to climate change. Climate Change Impacts and Adaptation Res. Rep. 70pp (2008).

9. Yaglou, C. P. \& Minard, D. Control of heat casualties at military training centers. A. M. A. Arch. Ind. Health 16, 302-316 (1957).

10. Epstein, Y. \& Moran, D. S. Thermal comfort and the heat stress indices. Ind. Health 44, 388-398 (2006).

11. Saji, N. H., Goswami, B. N., Vinayachandran, P. N. \& Yamagata, T. A dipole mode in the tropical Indian Ocean. Nature 401, 360-363 (1999).

12. Guan, Z. \& Yamagata, T. The unusual summer of 1994 in East Asia: IOD teleconnections. Geophys. Res. Lett. 30, 1544, doi:10.1029/2002GL016831 (2003).

13. Steadman, R. G. A universal scale of apparent temperature. J. Appl. Meteorol. 23, 1674-1687 (1984).

14. Rayner, N. A. et al. Global analyses of sea surface temperature, sea ice, and night marine air temperature since the late nineteenth century. J. Geophys. Res. 108, 4407, doi: 10.1029/2002JD002670 (2003).

\section{Acknowledgments}

We use the death toll data by heatstroke provided by the Ministry of Health, Labor and Welfare and the data after 2002 available online (http://www.e-stat.go.jp/SG1/estat/ OtherList.do?bid $=000001041668 \&$ cycode $=7$ ). This research was supported by the Environment Research and Technology Development Fund (2-1405) of the Ministry of the Environment, Japan.

\section{Author contributions}

A.T. conducted the analysis. A.T., Y.M. and S.K.B. wrote the manuscript together.

\section{Additional information}

Competing financial interests: The authors declare no competing financial interests. 
How to cite this article: Akihiko, T., Morioka, Y. \& Behera, S.K. Role of climate variability in the heatstroke death rates of Kanto region in Japan. Sci. Rep. 4, 5655; DOI:10.1038/ srep05655 (2014)

(c) (i) (-) This work is licensed under a Creative Commons Attribution-NonCommercialChareAlike 4.0 International License. The images or other third party material in this article are included in the article's Creative Commons license, unless indicated otherwise in the credit line; if the material is not included under the Creative Commons license, users will need to obtain permission from the license holder in order to reproduce the material. To view a copy of this license, visit http:// creativecommons.org/licenses/by-nc-sa/4.0/ 